\title{
Integrating geriatric assessment in the first line chemotherapy treatment in older patients with metastatic colorectal cancer: Results of a prospective observational cohort study (AVAPLUS)
}

\author{
Lore Decoster $^{\mathrm{a}, *}$, Cindy Kenis ${ }^{\mathrm{b}}$, Benedicte Naessens ${ }^{\mathrm{c}}$, Ghislain Houbier ${ }^{\mathrm{d}}$, Marc De Man ${ }^{\mathrm{e}}$, Guy Lambrecht ${ }^{\mathrm{f}}$, \\ Els Monsaert ${ }^{\mathrm{g}}$, Veerle Moons ${ }^{\mathrm{h}}$, Philippe Vergauwe ${ }^{\mathrm{i}}$, Hans Prenen ${ }^{\mathrm{j}}$, Eric Van Cutsem ${ }^{\mathrm{j}}$, Hans Wildiers ${ }^{\mathrm{k}}$ \\ a Department of Medical Oncology, Vrije Universiteit Brussel (VUB), Universitair Ziekenhuis Brussel (UZ Brussel), Laarbeeklaan 101, 1090 Brussels, Belgium \\ b Department of General Medical Oncology and Geriatric Medicine, University Hospitals Leuven, 3000 Leuven, Belgium \\ ' Department of Gastroenterology, AZ Nikolaas, Moerlandstraat 1, 9100 Sint-Niklaas, Belgium \\ d Department of Gastroenterology, CHC Liège, Rue de Hesbaye 75, 4000 Liège, Belgium \\ e Department of Gastroenterology, UZ Gent, De Pintelaan 185, 9000 Gent, Belgium \\ ${ }^{\mathrm{f}}$ Department of Gastroenterology, AZ Damiaan, Gouwelozestraat 100, 8400 Oostende, Belgium \\ ${ }^{g}$ Department of Gastroenterology, AZ Maria Middelares, Buitenring Sint-Denijs 30, 9000 Gent, Belgium \\ ${ }^{\mathrm{h}}$ Department of Gastroenterology, Imelda Ziekenhuis, Imeldalaan 9, 2820 Bonheiden, Belgium \\ i Department of Gastroenterology, AZ Groeninge, President Kennedylaan 4, 8500 Kortrijk, Belgium \\ j Department of Gastroenterology, University Hospitals, Leuven, Herestraat 49, 3000 Leuven, Belgium \\ k Department of Medical Oncology, University Hospitals Leuven, Department of Oncology, KU Leuven, Herestraat 49, 3000 Leuven, Belgium
}

\section{A R T I C L E I N F O}

Article history:

Received 22 May 2017

Received in revised form 8 September 2017

Accepted 13 October 2017

Available online $\mathrm{xxxx}$

\section{Keywords:}

Older patients

Metastatic colorectal cancer

Chemotherapy

Bevacizumab geriatric assessment

\begin{abstract}
A B S T R A C T
Objectives: This study aims to investigate the use of chemotherapy with or without bevacizumab in older patients with metastatic colorectal cancer (mCRC) in current daily practice and to identify predictive parameters for treatment-related outcomes.

Patients and Methods: This is a Belgian multi-centre, observational cohort study. Patients $\geq 70$ years old with $\mathrm{mCRC}$ considered suitable for first-line chemotherapy were eligible for inclusion. At baseline geriatric screening and assessment was performed. Treatment choice was at the discretion of the investigator. Treatment duration, Progression Free Survival (PFS) and safety were recorded.

Results: Between August 2011 and July 2013, 252 patients with mCRC were included of which 50.8\% were treated with bevacizumab. Median treatment duration was 5.5 months and median PFS was 8.9 months. Approximately $50 \%$ of patients experienced severe adverse events, most frequently diarrhea. In multivariate analysis, baseline Eastern Cooperative Oncology Group (ECOG)-performance status (PS) was predictive for treatment duration $(p=0.0047)$, PFS $(p<0.0001)$ and severe toxicity and baseline nutritional status for PFS ( $p=0.0007)$. In patients with a good ECOG-PS, nutritional status was predictive for PFS.

Conclusions: In current daily practice in Belgium, half of older patients with colorectal cancer treated with chemotherapy also receive bevacizumab. Nearly half of older patients presented with severe toxicity during treatment. Baseline nutritional status is a predictive marker for PFS. Patients with a baseline ECOG-PS $\geq 2$ have shorter PFS and higher risk of severe toxicity and should therefore be treated with caution.
\end{abstract}

(c) 2017 Elsevier Ltd. All rights reserved.

\section{Introduction}

With approximately 6500 new diagnoses each year in Belgium, colorectal cancer (CRC) is the second most frequently diagnosed cancer [1]. An important proportion is older patients with $58 \%$ of all Belgian CRC patients aged $\geq 70$ years and a mean age at diagnosis of 69.4 years for men and 71.1 years for women [2]. With the aging of the population,

* Corresponding author at: Department of Medical Oncology, Oncologisch Centrum, UZ Brussel, Laarbeeklaan 101, 1090 Brussels, Belgium.

E-mail address: lore.decoster@uzbrussel.be (L. Decoster). it is expected that the incidence of CRC in the older population will rise further.

Standard treatment of patients with metastatic CRC ( $\mathrm{mCRC}$ ) consists of combination chemotherapy with targeted agents such as bevacizumab or cetuximab [3]. However older patients with $\mathrm{mCRC}$ are underrepresented in most trials where the median age of patients is typically $<65$ years [4].

In randomized clinical trials in MCRC, bevacizumab demonstrated efficacy with different chemotherapy backbones [5-7]. In a pooled analysis of four randomized trials that assessed bevacizumab in with chemotherapy in mCRC, bevacizumab provided similar Progression 
Free Survival (PFS) and overall survival benefit in medically fit older patients as in younger patients, but an increased risk of thromboembolic events [8]. However, only $24 \%$ of patients in these randomized trials were 70 years or older and all were highly selected with good performance status (PS) and few comorbidities [8]. Therefore they are not representative for the older CRC population in daily clinical practice, which presents considerably more heterogeneity [9]. Patients with the same chronological age have different biological age based on their functional or cognitive status, comorbidities, and poly-pharmacy. This results in a risk for under-treatment in fit patients [10] or overtreatment with increased risk for treatment-related severe toxicity in frail patients. Geriatric assessment (GA) provides objective information on the overall health status, detects unknown geriatric problems, and guides the complex treatment decisions in older patients [11-13].

The aim of the present prospective observational cohort study was to complement the knowledge on first-line chemotherapy with or without bevacizumab in older patients with MCRC in current daily practice in Belgium and to evaluate the possible role of GA.

\section{Materials and Methods}

\subsection{Trial Design}

This observational study is a Belgian multi-centre, non-interventional, prospective cohort study.

Patients $\geq 70$ years old with previously untreated $\mathrm{mCRC}$ and considered suitable to receive first-line chemotherapy with or without bevacizumab were eligible for inclusion. Patients who met the eligibility criteria were identified by the treating physician before the start of the chemotherapy and enrolled consecutively after written informed consent.

Chemotherapy schedule, dosing and treatment duration were at the discretion of the investigator and in accordance with labelling.

The study was approved by the local institutional review boards at every participating site.

\subsection{Outcomes Assessments}

The scheduling of patients visits, method, and frequency of clinical assessments were part of routine care and were not carried out at protocol pre-specified fixed intervals and were not independently assessed. The exception was Eastern Cooperative Oncology Group (ECOG) PS [14], geriatric screening and GA, which were performed in all patients at baseline, preferably before the start of the planned treatment or if impossible within four weeks of treatment initiation.

The geriatric screening included the G8 and the Flemish version of the Triage Risk Screening Tool (fTRST) [11].

The GA included nine items: living situation (not alone, alone), activities of daily living (ADL) (independent, dependent), instrumental activities of daily living (IADL) (independent, dependent), MiniMental State Examination (MMSE) (normal, abnormal cognition), 15-item Geriatric Depression Scale (GDS-15) (not at risk for depression, at risk), Mini Nutritional Assessment (MNA) (normal, abnormal nutritional status), Charlson Comorbidity Index (CCI) (absence, presence of comorbidities), falls history (fall during the last year) and MobilityTiredness Test (Mob-T) (normal, abnormal mobility-related fatigue) [15-22].

The total GA score was calculated based on the presence of deficiencies on the seven following criteria: living alone, ADL score $>6$, IADL score $<5$ in men and $<8$ in women, MMSE score $<24$, GDS-15 score $\geq 5$, MNA score $<24$ and presence of at least one comorbidity on the $\mathrm{CCI}$. The higher the total GA score, the more deficiencies observed. A geriatric profile is defined as the presence of $\geq 2$ criteria.

Treatment duration was defined as the time interval between the first and the last, first-line mCRC treatment administration, which is the time to treatment failure for any reason.
PFS was defined as the time interval between initiation of first-line therapy and tumor progression evaluated in current practice or death from any cause, whichever comes first.

To evaluate toxicity, all adverse events (AEs) encountered during the study were to be reported and their intensity and relationship to chemotherapy or bevacizumab therapy was determined by the investigator. AEs of special interest for bevacizumab were recorded. Intensity of AEs was graded by the treating physician on a 3-point scale: mild: discomfort noticed but no disruption of normal daily activity; moderate: discomfort sufficient to reduce or affect daily activity; severe: inability to work or perform normal daily activity.

\subsection{Statistical Analysis}

The study being observational, no formal sample size calculation was performed. The safety population included all patients with at least one documented dose of chemotherapy, the reference population excluded patients with a major protocol deviation.

The primary endpoint was treatment duration. Secondary endpoints were PFS, toxicity, and GA results. PFS results were analysed on the reference population, all other results on the safety population.

The statistical methods were mainly descriptive. Continuous variables were presented using the number of observed values, mean, standard deviation (SD), median, minimum and maximum. Categorical variables were presented using numbers and percentages of patients.

Comparison of categorical data was performed using a Fisher exact test or a Chi square test when appropriate.

Treatment duration and PFS were described using Kaplan-Meier plots. For treatment duration, patients who were still under treatment at time of study withdrawal (because of consent withdrawal, lost to follow-up...) were censored on the last MCRC treatment date known. For PFS, patients who had neither progressed nor died at time of study end were censored on the date of study end.

To explore associations between treatment-related variables (treatment duration, PFS and severe toxicity) and the different geriatric screening and GA components, univariate and multivariate analyses were performed. In the univariate analyses, log-rank tests for treatment duration and PFS and Wilcoxon or Student t-tests for severe toxicity were used. Multivariate analyses used a stepwise approach. For the selection of covariates, the association between each covariate and the dependent variable was analysed in a univariate way using logistic regression models for severe toxicity, and Cox regression models for treatment duration and PFS. Covariates with a p-value $<0.075$ were selected. The covariates selected in the previous step were introduced in the multivariate model (logistic regression model for severe toxicity and Cox regression model for treatment duration and PFS). Then a stepwise (for logistic regression model) or a backward (for Cox regression model) selection was used to retain only independently significant covariates at the threshold of $5 \%$. Univariate and multivariate analyses were repeated considering only patients with an ECOG-PS value $<2$ at baseline.

Data analyses were performed using SAS software version 9.4. All statistical tests were two-sided at the $5 \%$ significance level, and corresponding 95\% CI were reported as appropriate.

\section{Results}

\subsection{Patient Characteristics}

Between August 2011 and July 2013, 34 Belgian centres screened a total of 254 patients (Fig. 1). Of these patients, 252 received at least one dose of chemotherapy and were included in the safety population. Of these 252 patients, 128 were treated with bevacizumab-containing chemotherapy and 124 patients received chemotherapy without bevacizumab. In this group of non-bevacizumab patients, eight patients were treated with cetuximab. Due to major protocol deviations, two patients were excluded from the reference population with PFS data; one 


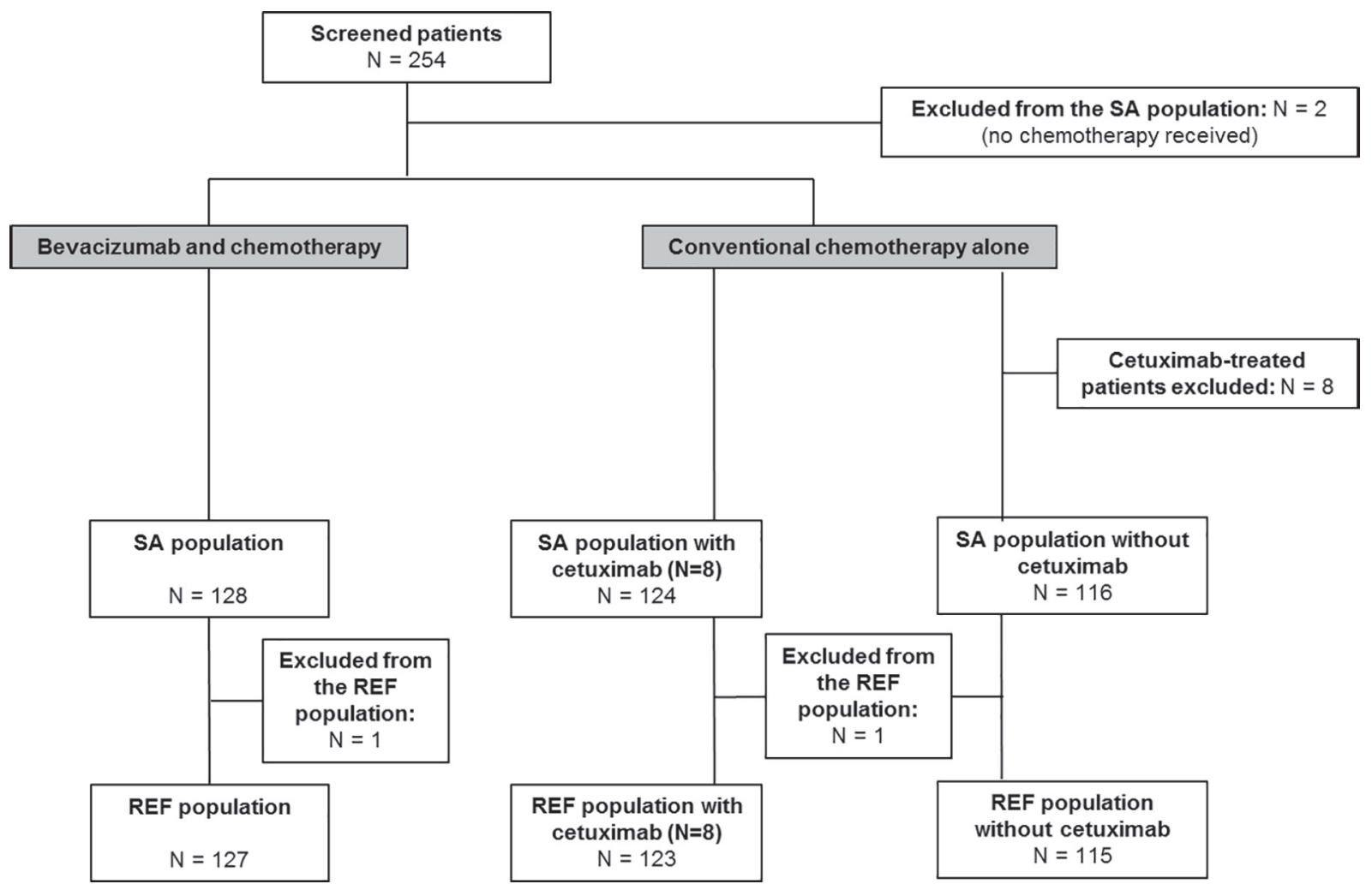

Legend: SA: Safety population; REF: Reference population

Fig. 1. Patient flow chart. Legend: SA: safety population; REF: reference population.

patient in the bevacizumab-containing chemotherapy group was younger than 70 years ( $69 \mathrm{y}$ ) and one patient in the non-bevacizumab chemotherapy group did not have $\mathrm{MCRC}$.

Baseline characteristics of patients are presented in Table 1. Median age for the total population was 77.4 years and $61.5 \%$ of patients were male. When compared to patients treated with bevacizumab, patients treated without bevacizumab were significantly older (mean 78.0 years versus 76.9 years, $p=0.039$ ), received significantly more single agent chemotherapy compared to combination chemotherapy (29.8\% versus $1.6 \% ; \mathrm{p}<0.001$ ) and were significantly more treated with antithrombotic agents at baseline $(53.2 \%$ versus $37.5 \%, \mathrm{p}=0.016)$.

\subsection{Treatment Duration and PFS Results}

Median treatment duration in the total population was 5.5 months (95\% CI; 5.1-6.2) with a median of 6.5 months (95\% CI; 5.5-7.4) for patients treated with bevacizumab-containing chemotherapy and 4.8 months (95\% CI; 6.9-9.8) for patients treated without bevacizumab.

Median PFS in the total population was 8.9 months (95\% CI; 7.9-9.9) with a median PFS of 9.2 months (95\% CI; 8.0-11.2) for the bevacizumab-group and 8.7 months $(95 \% \mathrm{CI} ; 6.9-9.8)$ for the nonbevacizumab group.

\subsection{Geriatric Screening and GA Results}

Results of ECOG-PS, geriatric screening and GA at baseline are listed in Table 2.

For 36 (14.6\%) patients an ECOG-PS score $\geq 2$ was observed. A geriatric risk profile was observed in 201 (81.0\%) patients with the G8 (cut off $\leq 14$ ) and in 195 (78.9\%) patients with the fTRST (cut off $\geq 1$ ). GA demonstrated a presence of at least two out of seven deficiencies in 153 (66.8\%) patients. Deficiencies were most frequently observed for comorbidities (54.4\%) and for nutritional status (54.2\%). At baseline, patients treated with bevacizumab had significant less abnormal fTRST scores ( $72 \%$ vs $86.1 \%, p=0.008$ ), less ADL deficiencies $(23.4 \%$ vs $44.7 \%, \mathrm{p}<0.001)$ and less cognitive decline ( $4.8 \%$ vs $15.6 \%, \mathrm{p}=0.006$ ).

\subsection{Safety Results}

A total of 247 patients (98.0\%) experienced AEs of any grade and 125 patients (49.6\%) experienced severe AEs, regardless of the association with bevacizumab ( 65 patients $(50.8 \%$ ) in the bevacizumab group and 60 patients (48.4\%) in the non-bevacizumab group). The most common severe $\mathrm{AE}$ was diarrhea, which was reported by 18 patients $(14.1 \%)$ of the bevacizumab group and 10 patients $(8.1 \%)$ of the nonbevacizumab group.

Recorded AEs of special interest to bevacizumab are summarized in Table 3. Of the patients treated with bevacizumab-containing chemotherapy, $16.4 \%$ experienced epistaxis, $14.1 \%$ a venous thrombotic event, $13.3 \%$ hypertension, $5.5 \%$ gastrointestinal bleeding and $4.7 \%$ proteinuria. There were 5 (3.9\%) severe venous thrombotic events, 2 (1.6\%) intestinal perforations and $1(0.8 \%)$ severe arterial thrombotic event.

In the bevacizumab-containing chemotherapy group, one patient (0.8\%) experienced an AE leading to death related to bevacizumab (intestinal perforation) and 4 patients (3.1\%) experienced AEs leading to death related to chemotherapy. In the non-bevacizumab chemotherapy group, 4 patients (3.2\%) experienced AEs leading to death related to chemotherapy.

\subsection{Associations With Geriatric Screening and Geriatric Assessment Components}

Univariate analysis was used to explore possible associations with geriatric screening and GA components and initial treatment decisions 
Table 1

Patient characteristics at baseline - safety population.

\begin{tabular}{|c|c|c|c|c|}
\hline & $\begin{array}{l}\text { Total } \\
\text { population } \\
(\mathrm{N}=252)\end{array}$ & $\begin{array}{l}\text { Chemotherapy } \\
\text { with } \\
\text { bevacizumab } \\
(\mathrm{N}=128)\end{array}$ & $\begin{array}{l}\text { Chemotherapy } \\
\text { without } \\
\text { bevacizumab } \\
(\mathrm{N}=124)\end{array}$ & $\begin{array}{l}\mathrm{p} \\
\text { value }\end{array}$ \\
\hline Mean age, years (range) & $77.4(69-91)$ & $76.9(69-89)$ & $78.0(70-91)$ & 0.039 \\
\hline Sex (\%) & & & & 0.301 \\
\hline Male & $155(61.5)$ & $83(65 \%)$ & $72(58 \%)$ & \\
\hline Female & $97(38.5)$ & $45(35 \%)$ & $52(42 \%)$ & \\
\hline \multicolumn{4}{|c|}{ Chemotherapy treatment (\%) } & $<0.001$ \\
\hline CAPOX or FOLFOX & $82(32.5)$ & $41(32.0 \%)$ & $41(33.1 \%)$ & \\
\hline FOLFIRI & $131(52)$ & $85(66.4 \%)$ & $46(37.1 \%)$ & \\
\hline $5 \mathrm{FU} / \mathrm{LV}$ or $\mathrm{CAP}$ & $39(15.5)$ & $2(1.6 \%)$ & $37(29.8 \%)$ & \\
\hline $\begin{array}{l}\text { Number of metastases } \\
(\%)\end{array}$ & & & & 0.059 \\
\hline 1 location & $154(61.1)$ & $71(55.5 \%)$ & $83(66.9 \%)$ & \\
\hline 2 locations & $82(32.5)$ & $45(35.2 \%)$ & $37(29.8 \%)$ & \\
\hline$>2$ locations & $16(6.3)$ & $12(9.4 \%)$ & $4(3.2 \%)$ & \\
\hline \multicolumn{4}{|c|}{ Primary tumor location (\%) } & 0.289 \\
\hline Colon ascending & $65(34.6)$ & $32(25.0 \%)$ & $33(26.6 \%)$ & \\
\hline $\begin{array}{l}\text { Colon } \\
\text { descending/transverse }\end{array}$ & $21(11.2)$ & $10(7.8 \%)$ & $11(8.9 \%)$ & \\
\hline Sigmoid & $102(54.3)$ & $52(40.6 \%)$ & $50(40.3 \%)$ & \\
\hline Rectum & $64(25.4)$ & $34(26.6 \%)$ & $30(24.2 \%)$ & \\
\hline ECOG-PS (\%) & $\mathrm{N}=247$ & $N=125$ & $\mathrm{~N}=122$ & 0.558 \\
\hline$<2$ & $211(85.4)$ & $61(48.8 \%)$ & $52(42.6 \%)$ & \\
\hline$\geq 2$ & $36(14.6)$ & $16(12.8 \%)$ & $20(16.4 \%)$ & \\
\hline $\begin{array}{l}\text { Ongoing medication at } \\
\text { baseline (\%) }\end{array}$ & & & & 0.077 \\
\hline$<5$ & $131(52)$ & $74(57.8 \%)$ & $57(46.0 \%)$ & \\
\hline$\geq 5$ & $121(48)$ & $54(42.2 \%)$ & $67(54.0 \%)$ & \\
\hline Antithrombotic agents & $114(45.2)$ & $48(37.5 \%)$ & $66(53.2 \%)$ & 0.016 \\
\hline \multicolumn{5}{|l|}{ Comorbidities (\%) } \\
\hline Hypertension & $142(56.3)$ & $70(54.7 \%)$ & $72(58.1 \%)$ & 0.613 \\
\hline Diabetes mellitus & $45(17.8)$ & $23(18.0 \%)$ & $22(17.7 \%)$ & 1 \\
\hline
\end{tabular}

Legend: CAPOX: capecitabine and oxaliplatin; FOLFOX: fluorouracil, leucovorin and oxaliplatin; FOLFIRI: fluorouracil, leucovorin and irinotecan; 5FU/LV: fluorouracil and leucovorin; CAP: capecitabine; ECOG-PS Eastern Cooperative Oncology Group-Performance Status.

Bold values indicate significant $\mathrm{p}$ values.

or treatment-related outcomes such as treatment duration, PFS and severe toxicity.

In univariate analysis, initial treatment decision (chemotherapy backbone, bevacizumab or not) was significantly associated with baseline fTRST score, ADL score, and total GA score. The mean fTRST score was significantly lower in patients treated with combination chemotherapy versus patients treated with single-agent chemotherapy (1.4 for capecitabin-oxaliplatin (CAPOX)/folinic acid-fluorouraciloxaliplatin (FOLFOX), 1.5 for folinic acid-fluorouracil-irinotecan (FOLFIRI) and 2.1 for fluorouracil-folinic acid (5FU/LV)-capecitabin $(\mathrm{CAP}) ; \mathrm{p}=0.025$ ) and in patients treated with versus without bevacizumab ( 1.3 versus $1.8 ; \mathrm{p}=0.003$ ). The mean ADL score was significantly lower for patients treated with bevacizumab-containing chemotherapy compared to non-bevacizumab chemotherapy (6.6 versus 7.2; $\mathrm{p}<0.001$ ). However, no association between mean ADL score and chemotherapy backbone could be observed. The total GA score was $\geq 2$ in significantly more patients treated without bevacizumab versus patients treated with bevacizumab ( $75 \%$ versus $59 \%$; $p=0.008$ ).

In univariate analysis, treatment-related outcomes were associated with baseline G8, ECOG-PS and MNA. Treatment duration was significantly associated with baseline ECOG-PS (2.2 months for ECOG-PS $\geq 2$ versus 5.5 months for ECOG-PS = 1 and 6.2 months for ECOG-PS = 0; $\mathrm{p}=0.0006$ ) and MNA (4.7 months for abnormal MNA versus 6.7 months for normal MNA; $\mathrm{p}=0.0162)$. For PFS, significant associations were observed with G8 (8.7 months for abnormal G8 versus 11.4 months for normal G8; $\mathrm{p}=0.0208$ ), ECOG-PS (4.8 months for ECOG-PS $\geq 2$ versus 8.8 months for ECOG-PS 1 and 10.3 months for ECOG-PS 0; $<<0.0001$ ) and MNA ( 7.6 months for abnormal MNA versus
10.3 months for normal MNA; $\mathrm{p}=0.0001)$. Severe toxicity was significantly associated with ECOG-PS ( $\mathrm{p}<0.001)$ and G8 ( $\mathrm{p}=0.005)$.

No significant associations were observed with fTRST and treatment-related outcomes (Table 4).

In multivariate analysis, baseline ECOG-PS was predictive for treatment duration ( $\mathrm{p}=0.0047$ ) and baseline ECOG-PS and baseline MNA score were predictive for PFS ( $\mathrm{p}<0.0001$ and $\mathrm{p}=0.0007$ respectively) (Fig. 2). Finally multivariate regression model showed that patients with an ECOG-PS $\geq 2$ had a higher risk of having at least one severe $\mathrm{AE}$ (Odd ratio [OR]: 5.02, 95\% CI: 2.10-12.00) compared to patients with an ECOG-PS 0.

Univariate and multivariate analyses were repeated considering only patients with an ECOG-PS $<2$ at baseline. As a result, significant associations were no longer observed for baseline ECOG-PS scores. In univariate analysis with the ECOG-PS $<2$ subpopulation, only MNA was significantly associated with treatment duration $(p=0.0481)$ and with PFS ( $\mathrm{p}=0.0012$ ) and G8 was associated with severe toxicity $(\mathrm{p}=0.018)$. In the multivariate analysis, MNA was the only predictor for PFS ( $p=0.0014)$.

\section{Discussion}

Although mCRC is predominantly a disease associated with advanced age, treatment guidelines are largely based on data from randomized trials involving only a small number of usually fit older patients. It is unclear whether treatment regimens that are beneficial for younger patients are also the best choice for the older population given their heterogeneity in physiological reserves, comorbidities, functional status, and cognition. This heterogeneity provides a major challenge, requiring an individualized and multidisciplinary approach. mCRC patients aged $\geq 75$ years and patients with higher comorbidity scores have a lower likelihood of receiving systemic chemotherapy and/or targeted biologics in first-line compared to younger patients, which may reflect concerns with regards to toxicities and quality of life [10,23,24]. A growing number of published data of bevacizumab usage in older patients became available from large observational studies or meta-analysis of randomized trials [25-32].

In the present study half of patients were treated with chemotherapy in combination with bevacizumab. When compared to patients treated without bevacizumab, patients treated with bevacizumab were significantly younger and fitter according to the fTRST and the total GA score. The treatment duration of 6.5 months and PFS of 9.2 months observed with the bevacizumab chemotherapy combination in our study are in line with other observational studies in older patients. In our study, bevacizumab was mainly used in combination with irinotecan-based chemotherapy. In the large observational studies 'Bevacizumab Expanded Access Trial' (BEAT) [28] and 'Bevacizumab Regimens: Investigation of Treatment Effects and Safety' (BRiTE) [29] bevacizumab was mainly combined with oxaliplatin-based chemotherapy. In the BEAT study 1914 patients with an ECOG-PS of 0-1 were treated with bevacizumab-containing chemotherapy and $25 \%$ of patients were aged 70 or older. Average duration of bevacizumab exposure was 260 days and median PFS was 10.8 months [28]. The BRiTE study evaluated 1953 patients. 27.3\% of patients were between 65 and 74 years old and $18.6 \%$ were 75 or older [29]. There were $7 \%$ of patients with an ECOG-PS of $\geq 2$. In the overall population, median treatment duration of first-line chemotherapy was 5.7 months and median PFS was 9.9 months. In patients aged $\geq 75$, median PFS was 9.7 months. Results of the Czech national registry [30], the French ETNA cohort [27], the non-interventional CASSIOPEE study [32] and the single centre experience published by Ocvirk et al. [31] showed comparable outcomes in older patients. The meta-analysis by Pinto in frail older patients receiving fluoropyrimidine mono-chemotherapy found that adding bevacizumab to this mono-chemotherapy significantly improved PFS and overall survival [26]. The weighted pooled median PFS was 9.4 months (95\% CI, 8.2-11.2 months) with the bevacizumab 
Table 2

Geriatric screening and geriatric assessment baseline scores - safety population.

\begin{tabular}{|c|c|c|c|c|}
\hline & $\begin{array}{l}\text { Safety population } \\
\mathrm{N}=252(\%)\end{array}$ & $\begin{array}{l}\text { Chemotherapy with bevacizumab } \\
\mathrm{N}=128(\%)\end{array}$ & $\begin{array}{l}\text { Chemotherapy without bevacizumab } \\
\mathrm{N}=124(\%)\end{array}$ & $\mathrm{p}$ value \\
\hline ECOG-PS & $N=247$ & $\mathrm{~N}=125$ & $\mathrm{~N}=122$ & \\
\hline Good performance status (0-1) & $211(85.4)$ & $109(87.2)$ & $102(83.6)$ & 0.558 \\
\hline Poor performance status $(\geq 2)$ & $36(14.6)$ & $16(12.8)$ & $20(16.4)$ & \\
\hline G8 & $\mathrm{N}=248$ & $\mathrm{~N}=125$ & $\mathrm{~N}=123$ & \\
\hline Absence of a geriatric risk profile $(>14)$ & $47(19.0)$ & $29(23.2)$ & $18(14.6)$ & 0.105 \\
\hline Presence of a geriatric risk profile $(\leq 14)$ & $201(81.0)$ & $96(76.8)$ & $105(85.4)$ & \\
\hline fTRST & $N=247$ & $\mathrm{~N}=125$ & $\mathrm{~N}=122$ & \\
\hline Absence of a geriatric risk profile $(0)$ & $52(21.1)$ & $35(28.0)$ & $17(13.9)$ & 0.008 \\
\hline Presence of a geriatric risk profile $(\geq 1)$ & $195(78.9)$ & $90(72.0)$ & $105(86.1)$ & \\
\hline MNA & $\mathrm{N}=236$ & $\mathrm{~N}=121$ & $\mathrm{~N}=115$ & \\
\hline Normal nutritional status $(\geq 24)$ & $108(45.8)$ & $57(47.1)$ & $51(44.3)$ & 0.696 \\
\hline Abnormal nutritional status $(<24)$ & $128(54.2)$ & $64(52.9)$ & $64(55.7)$ & \\
\hline ADL & $\mathrm{N}=247$ & $\mathrm{~N}=124$ & $\mathrm{~N}=123$ & \\
\hline Independent (6) & $163(66.0)$ & $95(76.6)$ & $68(55.3)$ & $<0.001$ \\
\hline Dependent (>6) & $84(34.0)$ & $29(23.4)$ & $55(44.7)$ & \\
\hline IADL & $\mathrm{N}=239$ & $\mathrm{~N}=122$ & $\mathrm{~N}=117$ & \\
\hline Independent 5 (men) or 8 (women) & $141(59.0)$ & $78(63.9)$ & $63(53.8)$ & 0.117 \\
\hline Dependent $<5$ (men) or $<8$ (women) & $98(41.0)$ & $44(36.1)$ & $54(46.2)$ & \\
\hline MMSE & $\mathrm{N}=247$ & $\mathrm{~N}=125$ & $\mathrm{~N}=122$ & \\
\hline Normal cognitive function $(\geq 24)$ & $222(89.9)$ & $119(95.2)$ & $103(84.4)$ & 0.006 \\
\hline Abnormal cognitive function $(<24)$ & $25(10.1)$ & $6(4.8)$ & $19(15.6)$ & \\
\hline GDS-15 & $\mathrm{N}=245$ & $\mathrm{~N}=123$ & $\mathrm{~N}=122$ & \\
\hline Not at risk for depression $(<5)$ & $183(74.7)$ & $93(75.6)$ & $90(73.8)$ & 0.770 \\
\hline At risk for depression $(\geq 5)$ & $62(25.3)$ & $30(24.4)$ & $32(26.2)$ & \\
\hline Mob-T & $\mathrm{N}=247$ & $\mathrm{~N}=125$ & $\mathrm{~N}=122$ & \\
\hline Normal mobility related fatigue $(\leq 4)$ & $127(51.4)$ & $58(46.4)$ & $69(56.6)$ & 0.127 \\
\hline Abnormal mobility related fatigue $(>4)$ & $120(48.6)$ & $67(53.6)$ & $53(43.4)$ & \\
\hline $\mathrm{CCI}$ & $\mathrm{N}=241$ & $\mathrm{~N}=122$ & $\mathrm{~N}=119$ & \\
\hline Absence of comorbidities (0) & $110(45.6)$ & $53(43.4)$ & $57(47.9)$ & 0.519 \\
\hline Presence of comorbidities $(\geq 1)$ & $131(54.4)$ & $69(56.6)$ & $62(52.1)$ & \\
\hline Fall history & $N=248$ & $\mathrm{~N}=125$ & $\mathrm{~N}=123$ & \\
\hline No fall during the last year & $195(78.6)$ & $99(79.2)$ & $96(78.0)$ & 0.877 \\
\hline Fall during the last year & $53(21.4)$ & $26(20.8)$ & $27(22.0)$ & \\
\hline Living situation & $\mathrm{N}=252$ & $\mathrm{~N}=128$ & $\mathrm{~N}=124$ & \\
\hline Not living alone & $183(72.6)$ & $98(76.6)$ & $85(68.5)$ & 0.161 \\
\hline Living alone & $69(27.4)$ & $30(23.4)$ & $39(31.5)$ & \\
\hline Total GA score ${ }^{a}$ & $\mathrm{~N}=229$ & $\mathrm{~N}=116$ & $\mathrm{~N}=113$ & \\
\hline No geriatric profile $(<2)$ & $76(33.2)$ & $48(41.4)$ & $28(24.8)$ & 0.008 \\
\hline Geriatric profile $(\geq 2)$ & $153(66.8)$ & $68(58.6)$ & $85(75.2)$ & \\
\hline
\end{tabular}

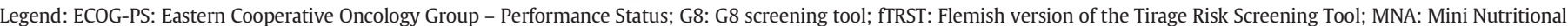

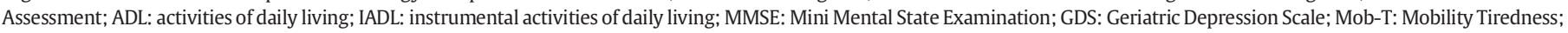
CCI: Charlson Comorbidity Index; GA: geriatric assessment.

Bold values indicate significant p values.

a Total GA score was based on the presence of the following criteria: living alone, ADL score $>6$, IADL score $<5$ in men and $<8$ in women, MMSE score $<24$, GDS- 15 score $\geq 5$, MNA total score $<24$ and presence of at least one comorbidity on the CCI

Table 3

All grade and severe adverse events of special interest to bevacizumab - safety population.

\begin{tabular}{|c|c|c|c|c|}
\hline & \multicolumn{2}{|c|}{$\begin{array}{l}\text { Chemotherapy with bevacizumab } \\
(\mathrm{N}=128)\end{array}$} & \multicolumn{2}{|c|}{$\begin{array}{l}\text { Chemotherapy without bevacizumab } \\
(\mathrm{N}=124)\end{array}$} \\
\hline & Adverse events & Severe adverse events & Adverse events & Severe adverse events \\
\hline Arterial thrombotic events & $3(2.3 \%)$ & $1(0.8 \%)$ & $2(1.6 \%)$ & $2(1.6 \%)$ \\
\hline Transient ischemic attack & $3(2.3 \%)$ & $1(0.8 \%)$ & $0(0.0 \%)$ & $0(0.0 \%)$ \\
\hline Myocardial infarct & $0(0.0 \%)$ & $0(0.0 \%)$ & $1(0.8 \%)$ & $1(0.8 \%)$ \\
\hline Cerebral thrombosis & $0(0.0 \%)$ & $0(0.0 \%)$ & $1(0.8 \%)$ & $1(0.8 \%)$ \\
\hline Venous thrombotic events & $18(14.1 \%)$ & $5(3.9 \%)$ & $9(7.3 \%)$ & $4(3.2 \%)$ \\
\hline Deep venous thrombosis & $4(3.1 \%)$ & $2(1.6 \%)$ & $4(3.2 \%)$ & $2(1.6 \%)$ \\
\hline Venous thrombosis & $2(1.6 \%)$ & $0(0.0 \%)$ & $0(0 \%)$ & $0(0.0 \%)$ \\
\hline Pulmonary embolism & $10(7.8 \%)$ & $3(2.3 \%)$ & $5(4.0 \%)$ & $2(1.6 \%)$ \\
\hline Portal vein thrombosis & $1(0.8 \%)$ & $0(0.0 \%)$ & $0(0.0 \%)$ & $0(0.0 \%)$ \\
\hline Mesenteric vein thrombosis & $1(0.8 \%)$ & $0(0.0 \%)$ & $0(0.0 \%)$ & $0(0.0 \%)$ \\
\hline Embolism & $1(0.8 \%)$ & $1(0.8 \%)$ & $1(0.8 \%)$ & $0(0.0 \%)$ \\
\hline Ischemic colitis & $1(0.8 \%)$ & $1(0.8 \%)$ & $0(0.0 \%)$ & $0(0.0 \%)$ \\
\hline Hypertension & $17(13.3 \%)$ & $2(1.6 \%)$ & $10(8.1 \%)$ & $2(1.6 \%)$ \\
\hline Proteinuria & $6(4.7 \%)$ & $0(0.0 \%)$ & $2(1.6 \%)$ & $0(0.0 \%)$ \\
\hline Epistaxis & $21(16.4 \%)$ & $0(0.0 \%)$ & $11(8.9 \%)$ & $0(0.0 \%)$ \\
\hline Intestinal perforation & $2(1.6 \%)$ & $2(1.6 \%)$ & $0(0.0 \%)$ & $0(0.0 \%)$ \\
\hline Gastrointestinal bleeding & $7(5.5 \%)$ & $1(0.8 \%)$ & $5(4.0 \%)$ & $0(0.0 \%)$ \\
\hline Cardiac failure & $1(0.8 \%)$ & $1(0.8 \%)$ & $1(0.8 \%)$ & $1(0.8 \%)$ \\
\hline
\end{tabular}


Table 4

Associations between geriatric assessment at baseline in univariate analysis - safety and reference population.

\begin{tabular}{|c|c|c|c|c|c|}
\hline GA score & $\begin{array}{l}\text { Chemotherapy with or } \\
\text { without bevacizumab }\end{array}$ & Chemotherapy backbone & Treatment duration & PFS & Severe toxicity \\
\hline ECOG-PS & $\mathrm{p}=0.278$ & $\mathrm{p}=0.385$ & $p=0.0006$ & $\mathrm{p}<0.0001$ & $\mathrm{p}<0.001$ \\
\hline G8 & $\mathrm{p}=0.305$ & $\mathrm{p}=0.758$ & $\mathrm{p}=0.0607$ & $p=0.0208$ & $\mathrm{p}=0.005$ \\
\hline fTRST & $\mathbf{p}=\mathbf{0 . 0 0 3}$ & $\mathbf{p}=\mathbf{0 . 0 2 5}$ & $\mathrm{p}=0.2880$ & $\mathrm{p}=0.4193$ & $\mathrm{p}=0.081$ \\
\hline MNA & $\mathrm{p}=0.706$ & $\mathrm{p}=0.667$ & $\mathrm{p}=\mathbf{0 . 0 1 6 2}$ & $\mathbf{p}=\mathbf{0 . 0 0 0 1}$ & $\mathrm{p}=0.120$ \\
\hline $\mathrm{ADL}$ & $\mathbf{p}<0.001$ & $\mathrm{p}=0.357$ & $\mathrm{p}=0.3462$ & $\mathrm{p}=0.1217$ & $\mathrm{p}=0.363$ \\
\hline IADL & $\mathrm{p}=0.507$ & $\mathrm{p}=0.946$ & $\mathrm{p}=0.6949$ & $\mathrm{p}=0.0994$ & $\mathrm{p}=0.238$ \\
\hline MMSE & $\mathrm{p}=0.081$ & $\mathrm{p}=0.449$ & $\mathrm{p}=0.0826$ & $\mathrm{p}=0.3671$ & $\mathrm{p}=0.843$ \\
\hline GDS-15 & $\mathrm{p}=0.478$ & $\mathrm{p}=0.213$ & $\mathrm{p}=0.9381$ & $\mathrm{p}=0.5714$ & $\mathrm{p}=0.301$ \\
\hline Mob-T & $\mathrm{p}=0.085$ & $\mathrm{p}=0.503$ & $\mathrm{p}=0.3616$ & $\mathrm{p}=0.1825$ & $\mathrm{p}=0.069$ \\
\hline $\mathrm{CCI}$ & $\mathrm{p}=0.829$ & $\mathrm{p}=0.371$ & $\mathrm{p}=0.8309$ & $\mathrm{p}=0.9574$ & $\mathrm{p}=0.066$ \\
\hline Fall history & $\mathrm{p}=0.825$ & $\mathrm{p}=0.695$ & $\mathrm{p}=0.8665$ & $\mathrm{p}=0.5555$ & $\mathrm{p}=0.439$ \\
\hline Total GA ${ }^{\mathrm{a}}$ score & $\mathbf{p}=\mathbf{0 . 0 0 8}$ & $\mathrm{p}=0.374$ & $\mathrm{p}=0.8595$ & $\mathrm{p}=0.4747$ & $\mathrm{p}=0.207$ \\
\hline
\end{tabular}

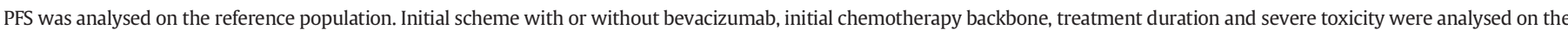
safety population.

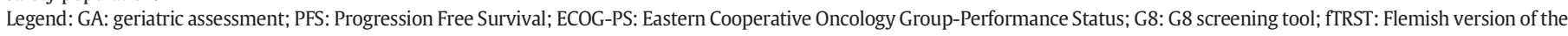

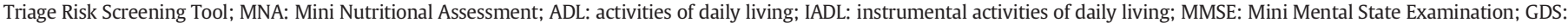
Geriatric Depression Scale; Mob-T: Mobility-Tiredness; CCI: Charlson Comorbidities Index.

Bold values indicate significant p values.

a Total GA score was based on the presence of the following criteria: living alone, ADL score $>6$, IADL score $<5$ in men, IADL score $<8$ in women, MMSE score $<24$, GDS $\geq 5$, MNA total score $<24$ and presence of at least one comorbidity on the CCI

combination and bevacizumab-based chemotherapy reduced the risk of progression by approximately 50\% compared to chemotherapy alone (HR, 0.52; 95\% CI, 0.43-0.64; $\mathrm{p}<0.00001$ ). The addition of bevacizumab to fluoropyrimidine monotherapy in patients unable to tolerate aggressive therapy is a possibility of the European Society for Medical Oncology (ESMO) consensus guidelines for the treatment of mCRC [3]. In our study, 39 (15.5\%) patients were treated with fluoropyrimidine monochemotherapy, but for only two patients this chemotherapy was combined with bevacizumab.

The observed safety profile of bevacizumab in this study was consistent with prospective randomized clinical trials and observational registry studies in $\mathrm{mCRC}$. In our study nearly half of patients presented with severe AEs (49.6\%), regardless of the addition of bevacizumab to the treatment regimen, with diarrhea being the most frequent severe AE. In the ETNA cohort with patients treated with first-line bevacizumab-FOLFIRI combination, severe diarrhea was significantly more observed in older patients compared to younger patients $(18.5 \%$ vs. $7.3 \%, p=0.002$ ) [27].

The most frequently observed bevacizumab-related AEs were epistaxis (16.4\%) venous thromboembolic events (14.1\%) and hypertension $(13.3 \%)$. One patient $(0.8 \%)$ experienced a severe arterial thrombotic event. Older patients treated in a real-life setting experienced comparable safety and effectiveness of bevacizumab-containing chemotherapy regimens compared to younger patients, but an increased risk of thromboembolic events has been reported $[8,27,33]$. Multivariate regression analysis in the observational BRiTE study identified baseline age $\geq 75$ years, ECOG-PS score $\geq 1$, anticoagulation and arterial disease history as significant independent risk factors for arterial thrombotic events [29,33]. Since quality of life is an important outcome in older patients with $\mathrm{mCRC}$, avoiding severe toxicity should be of high importance in this population. Chemotherapy toxicity prediction models such as the CRASH score [34] and the CARG score [35] were developed and validated to evaluate risk of toxicity. These prediction tools are based on GA, laboratory values, planned chemotherapy, age and tumor characteristics. A clear definition of frailty and the identification of increased risk for severe toxicity is still a subject of debate and there is still controversy regarding the most appropriate tools or assessments to identify frailty $[36,37]$.

Multivariate analysis in our study showed that ECOG-PS was associated with shorter treatment duration and PFS and higher risk of severe AEs. In the subpopulation of ECOG-PS $\geq 2$ patients with mCRC, treatment decisions should be taken with caution, carefully balancing potential benefits and possible AEs.
In the present study only $14.6 \%$ of patients presented with an ECOGPS $\geq 2$, while in $66.8 \%$ of patients at least two out of seven GA deficiencies were detected. In this heterogeneous $\mathrm{MCRC}$ population, commonly used PS scales therefore seem inferior to GA for making a clear distinction between fit and unfit patients, mainly because PS scales are normally assigned using cancer-related PS and not geriatric parameters such as non-cancer related functional status or comorbidities [38,39].

In our study, multivariate analysis in patients with an ECOG-PS $\leq 1$, only MNA was identified as predictive for PFS and no predictive markers for severe AEs were identified.

The present analysis has some limitations. First of all, this was an observational study for which no formal sample size calculation was performed. Therefore, the study was not powered to demonstrate significant differences in treatment duration and PFS between bevacizumab and non-bevacizumab groups. Also, PFS assessments were not carried out at protocol pre-specified fixed intervals and were not independently assessed. A large variation in visit intervals between the two treatment groups has been observed, possibly impacting the PFS outcomes. Mean (SD) number of days between two visits was 16.55 (9.39) days and 20.83 (17.61) days for bevacizumab-containing and non-bevacizumab chemotherapy respectively. This may be explained by the fact that in the bevacizumab group only 2 patients were treated with fluoropyrimidine monotherapy. In the nonbevacizumab group 37 (29.8\%) patients received fluoropyrimidine monotherapy. Indeed, since treatment decisions were left at the discretion of the treating physician, we observed a heterogeneous choice of chemotherapy. It should also be noted that some patients included in the non-bevacizumab group did receive bevacizumab at a later point and that some patients in the bevacizumab group stopped bevacizumab. This could have an impact on different treatmentrelated outcomes. In addition, even if investigators had to enroll consecutive patients who met the eligibility criteria, the risk of selection bias cannot be fully excluded. Finally, our multivariate models did not control for baseline characteristics such as age, sex or chemotherapy schedule.

Although this observational study was not powered to demonstrate significant differences in treatment outcomes between bevacizumab and non-bevacizumab groups, it should be acknowledged that only a slightly longer treatment duration (1.7 month difference) and no significantly higher PFS ( 0.5 months absolute difference) in the patients treated with bevacizumab compared to the group without bevacizumab was observed. Treatment decisions are complex in this heterogeneous population and include efficacy, safety and cost considerations. 
A

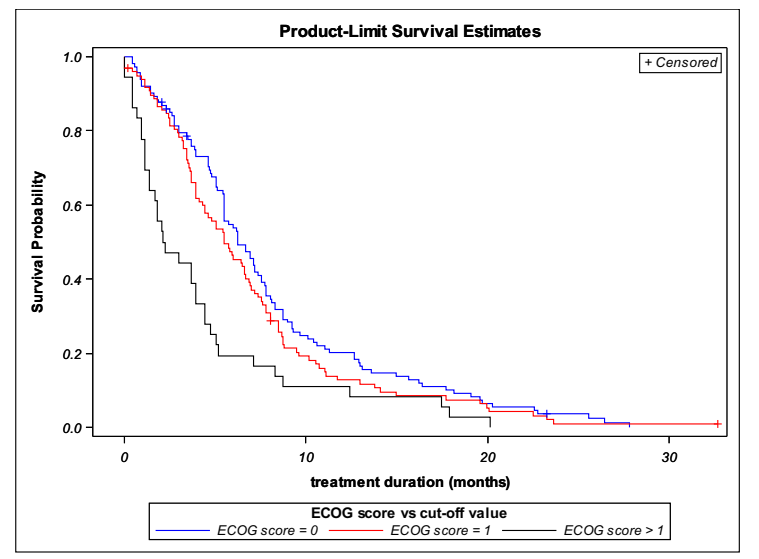

B

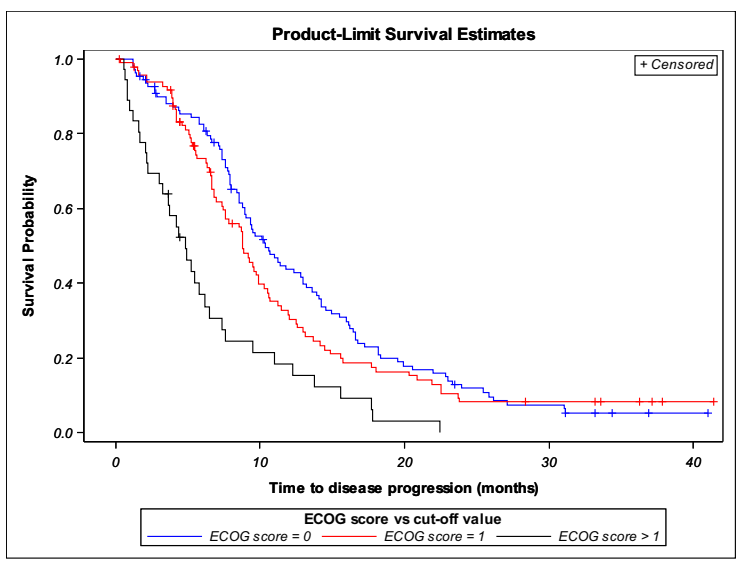

C

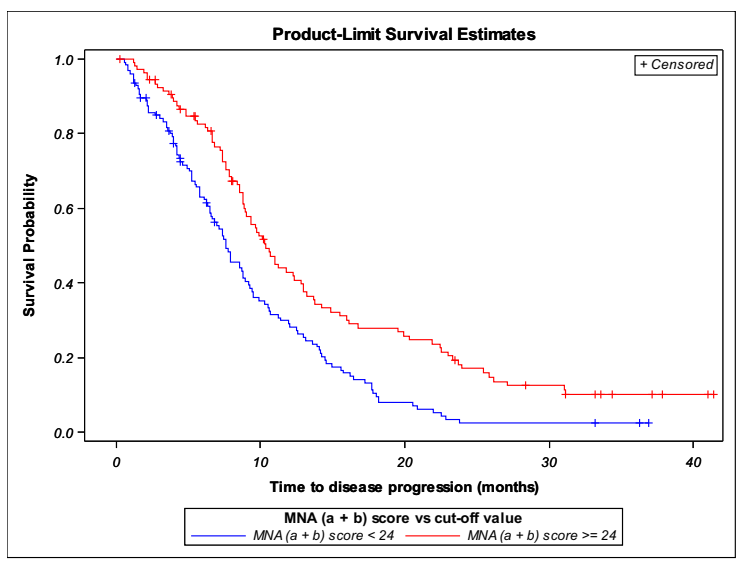

Legend: ECOG-PS: Eastern Cooperative Oncology Group - Performance Status; MNA: Mini Nutritional Assessment

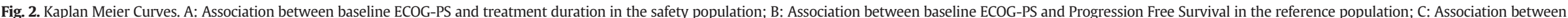
baseline Mini Nutritional Assessment and Progression Free Survival in the reference population Legend: ECOG-PS: Eastern Cooperative Oncology Group - Performance Status; MNA: Mini Nutritional Assessment. 
In this real-life first line setting of older patients with $\mathrm{mCRC}$, ECOGPS was identified as a predictor for treatment duration, PFS and severe toxicity, mainly driven by the small subpopulation of patients with ECOG-PS $\geq 2$. In multivariate analysis on patients with ECOG-PS $\leq 1$, which still contained many patients with geriatric deficits, MNA was the only predictor for PFS. The observed treatment duration and PFS of bevacizumab containing-chemotherapy was comparable to data found for older patients included in other observational studies with bevacizumab. In this group of older patients, the observed safety profile was consistent with the established safety profile in prospective randomized clinical trials and observational registry studies in the global mCRC population.

\section{Author Contributions}

Study concept: Lore Decoster, Cindy Kenis, Hans Wildiers, Eric Van Cutsem, Hans Prenen.

Study design: Lore Decoster, Cindy Kenis, Hans Wildiers, Eric Van Cutsem, Hans Prenen.

Data acquisition: all authors.

Quality control of data and algorithms: Cindy Kenis.

Data analysis and interpretation: Lore Decoster, Cindy Kenis, Hans Wildiers.

Statistical analysis: Lore Decoster, Keyrus Biopharma France.

Manuscript preparation: Lore Decoster, Cindy Kenis, Hans Wildiers.

Manuscript editing: Lore Decoster, Cindy Kenis.

Manuscript review: all authors.

\section{Disclosures and Conflict of Interest Statements}

Lore Decoster has attended advisory boards for Roche.

Hans Wildiers has received honoraria and research funding from Roche,

Pfizer, Leo Pharma, Teva, Amgen and Janssen.

All other authors have no relevant conflicts of interest to disclose.

\section{Funding}

The study was sponsored by Roche Belgium.

\section{Acknowledgments}

We thank patients and AVAPLUS investigators for making this study possible.

\section{References}

[1] Belgian Cancer Registry. http://www.kankerregister.org; 2016

[2] Incidence fact sheet, colorectal cancer, ICD10: C18-C20; Belgium 2013. Belgian Cancer Registry; 2015.

[3] Van Cutsem E, Cervantes A, Adem R, Sobrero A, Van Krieken JH, Aderka D, et al. ESMO consensus guidelines for the management of patients with metastatisc colorectal cancer. Ann Oncol 2016;27:1386-422.

[4] Papamichael D, Audision RA, Glimelius B, de Gramont A, Glynne-Jones R, Haller D, et al. Treatment of colorectal cancer in older patients: International Society of Geriatric Oncology (SIOG) consensus recommendations 2013. Ann Oncol 2015;26: 463-76.

[5] Hurwitz H, Fehrenbacher L, Novotny W, Cartwright T, Hainsworth J, Heim W, et al. Bevacizumab plus irinotecan, fluorouracil, and leucovorin for metastatic colorectal cancer. N Engl J Med 2004;350(23):2335-42.

[6] Saltz LB, Clarke S, Diaz-Rubio E, Scheithauer W, Figer A, Wong R, et al. Bevacizumab in combination with oxaliplatin-based chemotherapy as first-line therapy in metastatic colorectal cancer: a randomized phase III study. J Clin Oncol 2008;26(12): 2013-9.

[7] Giantonio BJ, Catalano PJ, Meropol NJ, O'Dwyer PJ, Mitchell EP, Alberts SR, et al. Bevacizumab in combination with oxaliplatin, fluorouracil, and leucovorin (FOLFOX4) for previously treated metastatic colorectal cancer: results from the Eastern Cooperative Oncology Group Study E3200. J Clin Oncol 2007;25(12): 1539-44.

[8] Cassidy J, Saltz LB, Giantonio BJ, Kabbinavar FF, Hurwitz HI, Rohr UP. Effect of bevacizumab in older patients with metastatic colorectal cancer: pooled analysis of four randomized studies. J Cancer Res Clin Oncol 2010;136(5):737-43.
[9] Lewis JH, Kilgore ML, Goldman DP, Trimble EL, Kaplan R, Montello MJ, et al. Participation of patients 65 years of age or older in cancer clinical trials. J Clin Oncol 2003; 21(7):1383-9.

[10] Aparicio T, Navazesh A, Boutron I, Bouarioua N, Chosidow D, Mion M, et al. Half of elderly patients routinely treated for colorectal cancer receive a sub-standard treatment. Crit Rev Oncol Hematol 2009;71(3):249-57.

[11] Decoster L, Van Puyvelde K, Mohile S, Wedding U, Basso U, Colloca G, et al. Screening tools for multidimensional health problems warranting a geriatric assessment in older cancer patients: an update on SIOG recommendations dagger. Ann Oncol 2015;26(2):288-300.

[12] Wildiers H, Heeren P, Puts M, Topinkova E, Janssen-Heijnen ML, Extermann M, et al. International Society of Geriatric Oncology consensus on geriatric assessment in older patients with cancer. J Clin Oncol 2014;32(24):2595-603.

[13] Aaldriks AA, Maartense E, Nortier HJ, van der Geest LG, le Cessie S, Tanis BC, et al. Prognostic factors for the feasibility of chemotherapy and the geriatric prognostic index (GPI) as risk profile for mortality before chemotherapy in the elderly. Acta Oncol 2016;55(1):15-23.

[14] Oken MM, Creech RH, Tormey DC, Horton J, Davis TE, McFadden ET, et al. Toxicity and response criteria of the Eastern Cooperative Oncology Group. Am J Clin Oncol 1982;5(6):649-55.

[15] Katz S, Ford AB, Moskowitz RW, Jackson BA, Jaffe MW. Studies of illness in the aged. The index of ADL: a standerdized measure of biological and psychosocial function. JAMA 1963;185:914-9.

[16] Lawton MP, Brody EM. Assessment of older people: self-maintaining and instrumental activities of daily living. Gerontologist 1969;9(3):179-86.

[17] Folstein MF, Folstein SE, McHugh PR. "Mini-mental state". A practical method for grading the cognitive state of patients for the clinician. J Psychiatr Res 1975;12(3): 189-98.

[18] Yesavage JA, Brink TL, Rose TL, Lum O, Huang V, Adey M, et al. Development and validation of a geriatric depression screening scale: a preliminary report. J Psychiatr Res 1982;17(1):37-49.

[19] Vellas B, Guigoz Y, Garry PJ, Nourhashemi F, Bennahum D, Lauque S, et al. The min nutritional assessment (MNA) and its use in grading the nutritional state of elderly patients. Nutrition 1999;15(2):116-22.

[20] Charlson ME, Pompei P, Ales KL, MacKenzie CR. A new method of classifying prognostic comorbidity in longitudinal studies: development and validation. J Chronic Dis 1987;40(5):373-83.

[21] Lamb SE, Jorstad-Stein EC, Hauer K, Becker C. Development of a common outcome data set for fall injury prevention trials: the prevention of falls network Europe consensus. J Am Geriatr Soc 2005;53(9):1618-22.

[22] Avlund K, Holstein BE. Functional ability among elderly people in three service settings: the discriminatory power of a new functional ability scale. Eur J Epidemiol 1998;14(8):783-90.

[23] Chan M, Hugh-Yeun K, Gresham G, Speers CH, Kennecke HF, Cheung WY Population-based patterns and factors associated with underuse of palliative systemic therapy in elderly patients with metastatic colon cancer. Clin Colorectal Cancer 2016.

[24] Parikh RC, XL Du, Morgan RO, Lairson DR. Patterns of treatment sequences in chemotherapy and targeted biologics for metastatic colorectal cancer: findings from a large community-based cohort of elderly patients. Drugs 2016;3(1):69-82.

[25] Doat S, Thiebaut A, Samson S, Ricordeau P, Guillemot D, Mitry E. Elderly patients with colorectal cancer: treatment modalities and survival in France. National data from the ThInDiT cohort study. Eur J Cancer 2014;50(7):1276-83.

[26] Pinto C, Antonuzzo L, Porcu L, Aprile G, Maiello E, Masi G, et al. Efficacy and safety of bevacizumab combined with fluoropyrimidine monotherapy for unfit or older patients with metastatic colorectal cancer: a systematic review and meta-analysis. Clin Colorectal Cancer 2016.

[27] Rouyer M, Fourrier-Reglat A, Smith D, Becouarn Y, Guimbaud R, Tubiana-Mathieu N et al. Effectiveness and safety of first-line bevacizumab plus FOLFIRI in elderly patients with metastatic colorectal cancer: results of the ETNA observational cohort. J Geriatr Oncol 2016;7(3):187-94.

[28] Van Cutsem E, Rivera F, Berry S, Kretzschmar A, Michael M, DiBartolomeo M, et al Safety and efficacy of first-line bevacizumab with FOLFOX, XELOX, FOLFIRI and fluoropyrimidines in metastatic colorectal cancer: the BEAT study. Ann Oncol 2009;20(11):1842-7

[29] Kozloff M, Yood MU, Berlin J, Flynn PJ, Kabbinavar FF, Purdie DM, et al. Clinica outcomes associated with bevacizumab-containing treatment of metastatic colorectal cancer: the BRiTE observational cohort study. Oncologist 2009;14(9): 862-70.

[30] Slavicek L, Pavlik T, Tomasek J, Bortlicek Z, Buchler T, Melichar B, et al. Efficacy and safety of bevacizumab in elderly patients with metastatic colorectal cancer: results from the Czech population-based registry. BMC Gastroenterol 2014; $14: 53$.

[31] Ocvirk J, Moltara ME, Mesti T, Boc M, Rebersek M, Volk N, et al. Bevacizumab plus chemotherapy in elderly patients with previously untreated metastatic colorectal cancer: single center experience. Radiol Oncol 2016;50(2):226-31.

[32] F E. Bevacizumab combined with 1st-line chemotherapy in elderly patients ( $\geq 75$ years-old) with metastatic colorectal cancer - interim results according to the chemotherapy regimen (CASSIOPEE). ASCO annual meeting ABST 3555; 2016

[33] Kozloff MF, Berlin J, Flynn PJ, Kabbinavar F, Ashby M, Dong W, et al. Clinical outcomes in elderly patients with metastatic colorectal cancer receiving bevacizumab and chemotherapy: results from the BRiTE observational cohort study. Oncology 2010;78(5-6):329-39.

[34] Extermann M, Boler I, Reich RR, Lyman GH, Brown RH, DeFelice J, et al. Predicting the risk of chemotherapy toxicity in older patients: the chemotherapy risk assessment scale for high-age patients (CRASH) score. Cancer 2012;118(13):3377-86. 
[35] Hurria A, Mohile S, Gajra A, Klepin H, Muss H, Chapman A, et al. Validation of a prediction tool for chemotherapy toxicity in older adults with cancer. J Clin Oncol 2016; 34(20):2366-71.

[36] Morley JE, Vellas B, van Kan GA, Anker SD, Bauer JM, Bernabei R, et al. Frailty consensus: a call to action. J Am Med Dir Assoc 2013;14(6):392-7.

[37] Huisingh-Scheetz M, Walston J. How should older adults with cancer be evaluated for frailty? J Geriatr Oncol 2017;8(1):8-15.
[38] Decoster L, Vanacker L, Kenis C, Prenen H, Van Cutsem E, Van Der Auwera J, et al. Relevance of geriatric assessment in older patients with colorectal cancer. Clin Colorectal Cancer 2016

[39] Jolly TA, Deal AM, Nyrop KA, Williams GR, Pergolotti M, Wood WA, et al. Geriatric assessment-identified deficits in older cancer patients with normal performance status. Oncologist 2015;20(4):379-85. 